\title{
Macrophage lipoprotein lipase promotes foam cell formation and atherosclerosis in vivo
}

\author{
Vladimir R. Babaev, ${ }^{1}$ Sergio Fazio, ${ }^{1,2}$ Linda A. Gleaves, ${ }^{1}$ Kathy J. Carter, ${ }^{1}$ \\ Clay F. Semenkovich, ${ }^{4}$ and MacRae F. Linton ${ }^{1,3}$ \\ ${ }^{1}$ Department of Medicine, \\ 2Department of Pathology, and \\ ${ }^{3}$ Department of Pharmacology, Vanderbilt University Medical Center, Nashville, Tennessee 37323, USA \\ ${ }^{4}$ Washington University, St. Louis, Missouri 63110-1043, USA \\ Address correspondence to: MacRae F. Linton, Division of Endocrinology, Vanderbilt University School of Medicine, \\ 715 Medical Research Building II, Nashville, Tennessee 37232-6303, USA. Phone: (615) 936-1653; Fax: (615) 936-1667; \\ E-mail: macrae.linton@mcmail.vanderbilt.edu.
}

Received for publication December 22, 1998, and accepted in revised form May 11, 1999.

\begin{abstract}
Expression of lipoprotein lipase (LPL) by the macrophage has been proposed to promote foam cell formation and atherosclerosis, primarily on the basis of in vitro studies. LPL-deficient mice might provide a model for testing the role of LPL secretion by the macrophage in an in vivo system. Unfortunately, homozygous deficiency of LPL in the mouse is lethal shortly after birth. Because the fetal liver is the major site of hematopoiesis in the developing fetus, transplantation of C57BL/6 mice with $\mathrm{LPL}^{-/}$fetal liver cells (FLCs) was used to investigate the physiologic role of macrophage LPL expression in vivo. Thirty-four female C57BL/6 mice were lethally irradiated and reconstituted with FLCs from day $14 \mathrm{LPL}^{+/+}$, $L P L^{+/-}$, and $L P L^{-/-}$donors. No significant differences were detected in plasma levels of post-heparin LPL activity or in serum cholesterol or triglyceride levels between the 3 groups on either a chow diet or an atherogenic diet. After 19 weeks on the atherogenic diet, aortae were collected for quantitative analysis of the extent of aortic atherosclerosis. LPL expression was detected by immunocytochemistry and in situ hybridization in macrophages of aortic atherosclerotic lesions of $\mathrm{LPL}^{+/+} \rightarrow \mathrm{C} 57 \mathrm{BL} / 6$ and $\mathrm{LPL}^{+/-} \rightarrow \mathrm{C} 57 \mathrm{BL} / 6$ mice, but not in $L P L^{-/-} \rightarrow C 57 B L / 6$ mice, whereas myocardial cells expressed LPL in all groups. The mean aortic lesion area was reduced by $55 \%$ in $\mathrm{LPL}^{-/-} \rightarrow \mathrm{C} 57 \mathrm{BL} / 6$ mice compared with $L P L^{+/+} \rightarrow C 57 \mathrm{BL} / 6$ mice and by $45 \%$ compared with $L P L^{+/-} \rightarrow C 57 B L / 6$ mice, respectively. These data demonstrate in vivo that LPL expression by macrophages in the artery wall promotes foam cell formation and atherosclerosis.
\end{abstract}

J. Clin. Invest. 103:1697-1705 (1999).

\section{Introduction}

Lipoprotein lipase (LPL), a 52-kDa glycoprotein, is the primary enzyme responsible for the hydrolysis of triglycerides in chylomicrons and VLDL, resulting in the production of chylomicron remnants and IDL (1). Adipose and muscle cells are the major sources of LPL synthesis; LPL is then secreted and transported to the luminal surface of the vascular endothelium, where it is bound to heparan sulfate proteoglycans (2). In addition, LPL is expressed by monocyte-derived macrophages and by macrophage-derived foam cells and smooth muscle cells in atherosclerotic lesions $(3,4)$. LPL has been proposed to influence the development and progression of atherosclerosis both by its crucial role in determining the composition of the plasma lipoproteins and by direct effects in the artery wall (5).

The effects of LPL on the atherogenicity of the plasma lipoprotein profile are dichotomous. Although the LPLinduced transformation of large nonatherogenic, triglyceride-rich lipoproteins into remnant lipoproteins and the generation of LDL cholesterol must be viewed as proatherogenic, the efficient lipolysis of triglyceride-rich lipoproteins, the promotion of rapid clearance of postprandial lipoproteins, and the generation of material for HDL formation are to be viewed as antiatherogenic effects of LPL (6). In addition, LPL has been proposed to influence atherogenesis by mechanisms that are independent of its catalytic actions on the plasma lipoproteins. An increasing amount of evidence indicates that LPL also functions as a ligand, associating with lipoproteins and promoting their binding to the LDL receptor-related protein (LRP) (7), LDL receptor (8), and extracellular proteoglycans (9). LPL may promote atherogenesis by increasing the binding and retention of LDL cholesterol by proteoglycans of the subendothelial matrix (10). LPL possesses domains that bind both apo B-containing lipoproteins and proteoglycans, permitting this bridging action (11). Recent studies in transgenic mice expressing catalytically inactive LPL from a muscle-specific promoter provide evidence for LPL bridging in vivo (12).

The physiologic role of LPL secretion by the macrophage in atherosclerosis is uncertain. On the basis primarily of in vitro studies, a number of functions of LPL expression by the macrophage have been proposed to promote foam cell formation and atherosclerosis. LPL increases monocyte adhesion to aortic endothelial cells, and LPL can function as a monocyte adhesion protein (13). Thus, macrophage LPL may promote macrophage recruitment to and retention in the vessel wall. Given its role in the metabolism of triglyceride-rich lipoproteins, LPL may contribute to the degradation and internalization of lipoproteins by the macrophage. Active LPL secreted by macrophages pro- 


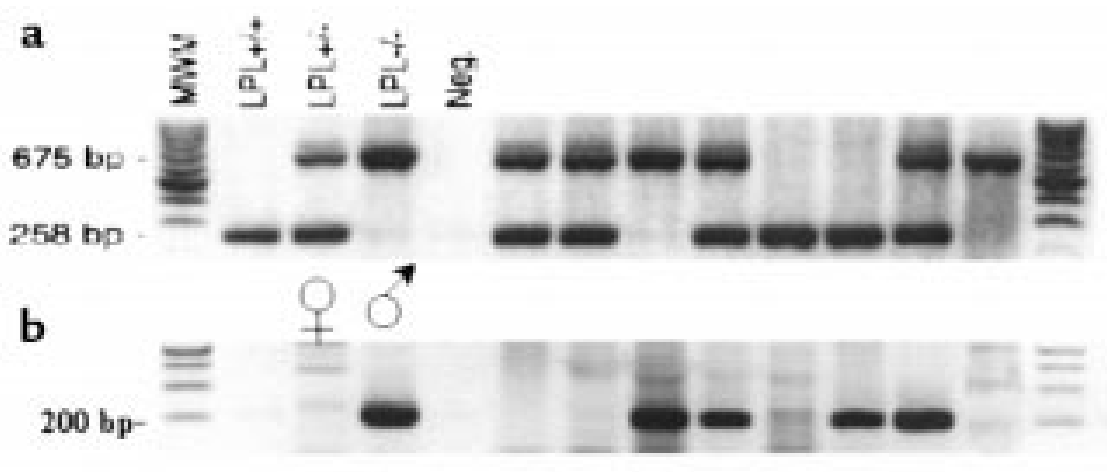

$\begin{array}{llllllllllllll}1 & 2 & 3 & 4 & 5 & 6 & 7 & 8 & 9 & 10 & 11 & 12 & 13\end{array}$

Figure 1

Rapid PCR for identification of LPL genotype and sex of fetuses. Tail tissue was digested in proteinase $K$ and used directly in PCR reaction. After PCR, the samples were separated on a $1.5 \%$ agarose gel containing ethidium bromide to view the DNA bands on ultraviolet illumination. (a) A combination of 3 oligonucleotide primers amplify a 258-bp band from exon 8 of the wild-type mouse LPL allele and a 675-bp band from the targeted LPL allele. Lanes 2-5 are control samples: $L P L^{+/+}, L P L^{+/-}, L P L^{-/-}$, and no DNA, respectively. Lanes 6-13 are DNA samples from 8 fetuses from the same litter. (b) Amplification of a 200-bp band from the Zfy gene of the Y chromosome indicates male sex. Lanes 3 and 4 are female and male control samples, respectively. Lanes 2 and 5 contain no DNA. Lanes 6-13 are DNA samples from the same 8 fetuses as in a. mammalian embryogenesis and that macrophages are the only leukocytes that express LPL, transplantation of wild-type C57BL/6 mice with $L P L^{-/-}$fetal hematopoietic cells offers an approach for the development of mice with a de facto macrophagespecific knockout of LPL expression.

To examine the physiologic role of the macrophage LPL expression in atherosclerosis and lipoprotein metabolism in vivo, mice chimeric for macrophage LPL gene expression were generated by transplanting female C57BL/6 mice with $\mathrm{LPL}^{-/-}, \mathrm{LPL}^{+/-}$, or $\mathrm{LPL}^{+/+}$fetal liver cells (FLCs). The current studies demonstrate that macrophage expression of LPL does not significantly contribute to the metabolism of plasma lipoproteins. However, under atherogenic conditions, LPL expression by macrophages in the artery wall promotes foam cell for-

motes chylomicron uptake by macrophages, and chylomicron remnants are known to promote cholesteryl ester accumulation by macrophages (14). The free fatty acids (FFA) produced by LPL-mediated hydrolysis can be re-esterified by macrophages (14), leading to cholesteryl ester accumulation in these cells (15). In addition, FFA may promote foam cell formation by stimulating intracellular acyl coenzyme A/cholesterol acyltransferase. Through its ligand and bridging functions, LPL increases the uptake of LDL cholesterol by the macrophage via the LDL receptor (15) and non-LDL receptor-mediated pathways, which may be enhanced by the bridging of LDL to heparan sulfate proteoglycans by LPL (11). LPL reduces apo E secretion by macrophages (16), which might result in a loss of the established antiatherogenic effects of macrophage apo E secretion. An association between high levels of LPL expression by peritoneal macrophages in vitro and susceptibility to atherosclerosis in certain inbred strains of mice has been reported, suggesting a proatherogenic role for macrophage expression of LPL (17). However, in vivo data regarding the physiologic role of macrophage LPL in atherosclerosis have been lacking.

Recent studies in our laboratory have demonstrated the utility of murine bone marrow transplantation experiments in examining the role of the macrophage apo E expression in atherosclerosis and lipoprotein metabolism $(18,19)$. A similar approach might prove useful in examining the role of macrophage LPL in atherosclerosis. Two groups have reported the production of LPL-deficient mice by gene-targeting techniques in embryonic stem cells $(20,21)$. Unfortunately, the homozygous $L P L^{-/-}$pups die soon after birth, making it difficult to identify viable offspring as donors for these experiments. Given that the fetal liver is the predominant organ of hematopoiesis during mation and atherosclerosis in vivo.

\section{Methods}

Animal procedures. Mice heterozygous for inactivation of the LPL gene by homologous recombination (20) were at the sixth backcross into the C57BL/ 6 background. Mice were maintained in microisolator cages on a rodent chow diet (catalog no. 5010; PMI Feeds Inc., St. Louis, Missouri, USA) containing $4.5 \%$ fat. All mice were given autoclaved acidified ( $\mathrm{pH} 2.8$ ) water. Animal care and experimental procedures were performed according to the regulations of Vanderbilt University's Animal Care Committee.

FLC isolation. Female $\mathrm{LPL}^{+/-}$mice were mated with $\mathrm{LPL}^{+/-}$ males, and pregnancy was determined by the presence of a vaginal plug. On day 14 of gestation, the pregnant mice were sacrificed by cervical dislocation. The embryos were dissected free from the placenta and yolk sac. The tails of fetuses were taken for LPL and gender genotyping. Fetal livers were placed in RPMI-1640 media (GIBCO BRL, Gaithersburg, Maryland, USA) containing $2 \%$ FCS on ice. A single-cell suspension of FLCs was prepared by sequentially passing the tissue-through syringes, fitted with G21 and G25 needles. The FLCs were diluted in $2 \%$ acetic acid, counted in a hemocytometer, and cryopreserved in a mixture containing $10 \%$ DMSO, 25\% FCS, and RPMI-1640 as described (22).

Rapid PCR genotyping and sex identification. To identify the LPL genotype of mouse fetuses, the tail tissue was digested in $100 \mu \mathrm{L}$ of mixture containing $10 \mu \mathrm{L}$ of $10 \times$ PCR buffer, $10 \mu \mathrm{L}$ of $25 \mathrm{mM}$ $\mathrm{MgCl} 2,10 \mu \mathrm{L}$ of $10 \%$ Brij-35 (Sigma Chemical Co., St. Louis, Missouri, USA), $5 \mu \mathrm{L}$ of proteinase $\mathrm{K}(20 \mathrm{mg} / \mathrm{mL})$, and $65 \mu \mathrm{L}$ of distilled water at $55^{\circ} \mathrm{C}$ for 30 minutes as described (23). Digested samples were incubated at $100^{\circ} \mathrm{C}$ for 10 minutes, vortexed, and chilled on ice. Five microliters of sample was mixed with a cocktail containing PCR buffer, $25 \mathrm{mM} \mathrm{MgCl}_{2}$, dNTP mix, primers, and DNA polymerase in $50 \mu \mathrm{L}$ of final volume. The combination of an upstream primer (5'-GACTTCCAGAAGTAACCAAC), a downstream primer corresponding to flanking regions of exon 8 (5'-ACTAGGTCCCACAGGACTG), and a primer from the neomycin cassette (5'-TCGCCTTCTATCGCCTTCTTGAG) was 


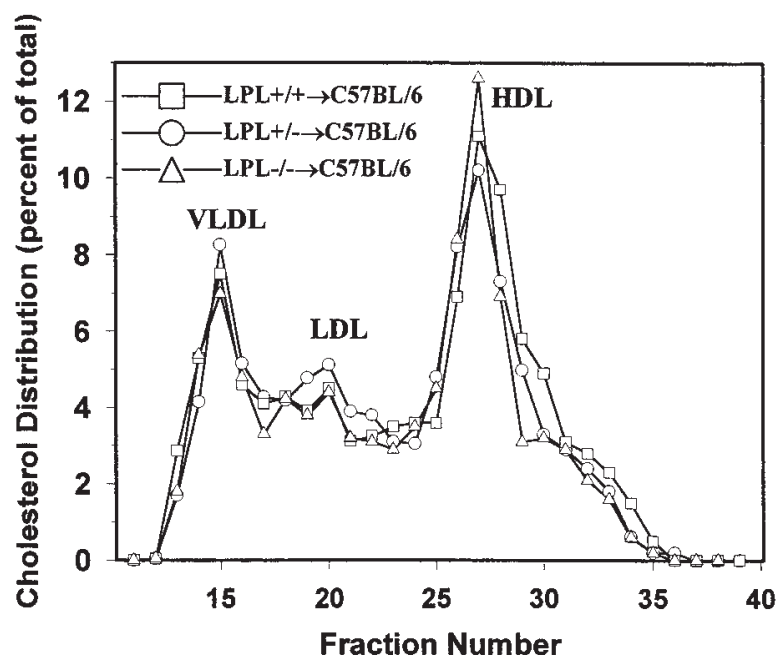

Figure 2

Lipoprotein distribution in C57BL/6 mice transplanted with $\mathrm{LPL}^{+/+}, \mathrm{LPL}^{+/-}$ and $L P L^{-/-}$FLCs after 8 weeks on the atherogenic diet. Mice were fasted for 4 hours. Lipoprotein distribution was determined by FPLC followed by cholesterol analysis of each fraction. Data are represented as an average $(n=3)$ percent distribution of total cholesterol. Fractions 14-17 contain VLDL; fractions 18-24 are IDL/LDL; and fractions 25-29 contain HDL. Fractions 30-40 are the non-lipoprotein-associated proteins.

used. A Rapidcycler (Idaho Technology, Idaho Falls, Idaho, USA) was used with the following parameters $\left(40\right.$ seconds at $94^{\circ} \mathrm{C}$ for the first cycle, followed by 30 cycles of 15 seconds at $94^{\circ} \mathrm{C}, 15 \mathrm{sec}-$ onds at $55^{\circ} \mathrm{C}$, and 35 seconds at $72^{\circ} \mathrm{C}$ ).

To identify the sex of the fetuses, the DNA samples were amplified in a PCR reaction using a pair of primers (GTAGGAAGAATCTTTCTCATGCTGG and TTTTTGAGTGCTGATGGGTGACGG) to detect the $Z f y$ gene present in the sexdetermined region of the $\mathrm{Y}$ chromosome (24). Amplification was performed in a thermal cycler (Perkin-Elmer Cetus, Norwalk, Connecticut, USA) using the following cycle steps: 10 minutes at $94^{\circ} \mathrm{C}$, followed by 1 minute at $94^{\circ} \mathrm{C}, 2$ minutes at $65^{\circ} \mathrm{C}$, and 3 minutes at $72^{\circ} \mathrm{C}$, for 30 cycles. The PCR product was obtained (as several bands about $200 \mathrm{bp}$ in length) in the male fetuses but not in the female fetuses.

FLC transplantation. From a week before to 2 weeks after transplantation, all recipient mice were given $100 \mathrm{mg} / \mathrm{L}$ neomycin and $10 \mathrm{mg} / \mathrm{L}$ polymyxin B sulfate (both from Sigma Chemical Co.) in acidified water. FLCs were thawed rapidly at $37^{\circ} \mathrm{C}$, washed in RPMI- 1640 containing $2 \%$ FBS, and counted again. Thirty-four 6-week-old female recipient C57BL/6 mice were lethally irradiated ( 9 Gy) from a cesium gamma source, and, 4 hours later, $5 \times 10^{6}$ cells in $300 \mathrm{~mL}$ of RPMI-1640 media were injected into the tail vein. After transplantation, the mice were placed on a rodent chow diet (catalog no. 5010; PMI Feeds Inc.) for 8 weeks and then on an atherogenic Butterfat Diet (ICN Pharmaceutical Inc., Costa Messa, California, USA) containing $19.5 \%$ fat, $1.25 \%$ cholesterol, and $0.5 \%$ cholic acid for 19 weeks.

Serum cholesterol and triglyceride analysis. Mice were fasted for 4 hours, and blood samples were collected by retro-orbital venous plexus puncture under metofane anesthesia. Serum was separated by centrifugation and preserved using $1 \mathrm{mM}$ phenylmethylsulfonyl fluoride (Sigma Chemical Co.). The concentration of total cholesterol and triglycerides was determined using Sigma kit nos. 352 and 339 adapted for microtiter plate assay. HDL cholesterol concentration was measured on an automated ACE analyzer using the Direct HDL Test (catalog no. 10981; Schiapparelli Biosystems Inc., Fairfield, New Jersey, USA).

Lipoprotein separation. Serum from mice was subjected to fast-performance liquid chromatography (FPLC) analysis using a Superose 6 column (Pharmacia Biotech Inc., Piscataway, New Jersey, USA) on an HPLC system model 600 (Waters Chromatography, Milford, Massachusetts, USA). A $100-\mu \mathrm{L}$ aliquot of serum was injected onto the column and separated with a buffer containing $0.15 \mathrm{M} \mathrm{NaCl}, 0.01 \mathrm{M}$

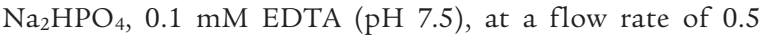
$\mathrm{mL} / \mathrm{min}$. Forty $0.5-\mathrm{mL}$ fractions were collected, and tubes 11-40 were analyzed for cholesterol. Fractions 14-17 contain VLDL and chylomicrons; fractions 18-24 contain LDL and IDL; fractions 25-29 contain HDL; and fractions 30-40 contain non-lipoprotein-associated proteins.

LPL activity assay. After a 4-hour fast, mice were injected with $200 \mathrm{U}$ heparin (Sigma Chemical Co.), and, 30 minutes later, blood was drawn from retro-orbital plexus and the plasma was frozen. To measure heart muscle tissue LPL activity, hearts were collected from mice after a 4-hour fast and tissue was homogenized in assay buffer as noted (20). LPL enzyme activity was determined as the salt-inhibitable ability of triplicate samples to hydrolyze a radiolabeled triolein emulsion as described previously (25).

Quantitation of arterial lesions. After 19 weeks on the Butterfat Diet, mice were sacrificed and flushed with $30 \mathrm{~mL}$ saline by slow injection through the left ventricle. The heart with aorta was embedded in OCT and snap-frozen in liquid nitrogen. Cryosections of $10-\mu \mathrm{m}$ thickness were taken from the region of the proximal aorta starting from the end of the aortic sinus and for $300 \mu \mathrm{m}$ distally, according to the method of Paigen et al. (26), adapted for computer analysis $(19,27)$. Cryosections were stained with oil red $\mathrm{O}$ and counterstained with hematoxylin. The images of the aorta were captured with a frame grabber (version 3.1; Kontron Electronik GmbH, Munich, Germany), using a color video camera (ZVS-3C75DE; Carl Zeiss Inc., Thornwood, New York, USA) mounted on an Axioskop microscope (Carl Zeiss Inc.) with a separate color video monitor (PVM-1353MD; Sony Corp., Kanagawa, Japan). Quantitative analysis of lipid-stained lesions was performed using an Imaging System KS 300 (Release 2.0; Kontron Electronik GmbH.).
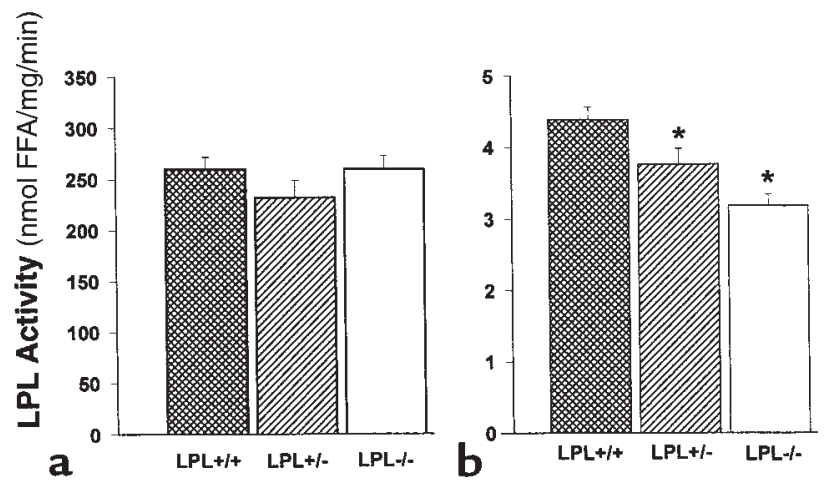

Figure 3

LPL activity in post-heparin plasma and heart tissue of C57BL/ 6 mice transplanted with $L P L^{+/+}, L P L^{+/-}$, and $L P L^{-/-}$FLCs. (a) Post-heparin plasma LPL activity. For analysis of plasma LPL activity, mice were fasted for 4 hours and then injected with $200 \mathrm{U}$ heparin (Sigma Chemical Co.) in PBS; 30 minutes later, mice were bled, post-heparin plasma was collected, and LPL activity was measured as described previously (20). (b) Heart tissue LPL activity. Hearts were collected from mice after a 4-hour fast, and the apex of each was snap-frozen in liquid nitrogen. The heart tissue was homogenized later in assay buffer as described previously (20). Data are represented as an average of the 3 mice per group. ${ }^{*} P<$ 0.05 vs. $\mathrm{LPL}^{+/+} \rightarrow \mathrm{C} 57 \mathrm{BL} / 6$ mice. 


\section{Figure 4}

Immunocytochemical detection of macrophages in the myocardium of $\mathrm{LPL}^{+/+} \rightarrow \mathrm{C} 57 \mathrm{BL} / 6$ mice. Macrophages are stained with rat mAb MOMA2 as the primary antibody, followed by biotinylated goat anti-rat $\lg G$ as the secondary antibody. The sections were incubated with avidin-biotin complex labeled with alkaline phosphatase, and the enzymatic activity was viewed with Fast Red TR/Naphthol AS-NX substrate. The sections were counterstained with hematoxylin. The primary antibody was omitted during the incubation of negative control sections, and no red staining was seen in these sections (data not shown). $\times 40$.
Color threshold was used to delimit the oil red O-stained lesion area that was measured as squared microns per animal. Immunocytochemistry. The localization of mouse LPL protein and macrophages in the arterial lesions was examined by immunocytochemistry using $5-\mu \mathrm{m}$ cryosections of the proximal aorta fixed in acetone at $4^{\circ} \mathrm{C}$. The sections were immersed in PBS ( $\mathrm{pH} 7.2)$ and incubated overnight at $4^{\circ} \mathrm{C}$ with either a chicken antibody to recombinant human LPL (a gift of Lawrence Chan, Baylor College, Houston, Texas, USA) (28) reacting with mouse $\mathrm{LPL}$, or with monoclonal rat antibody MOMA-2 (Accurate Chemical \& Scientific Corp., Westbury, New York, USA). The sections were treated with goat biotinylated antibodies to chicken IgG (Vector Laboratories, Burlingame, California, USA) or to rat IgG (PharMingen, San Diego, California, USA) for 45 minutes at $37^{\circ} \mathrm{C}$. Then, sections were incubated with avidin-biotin complex labeled with alkaline phosphatase (Vector Laboratories). Enzyme was viewed with Fast Red TR/Naphthol AS-NX substrate (Sigma Chemical Co.) and counterstained with hematoxylin. Nonimmune rabbit or rat serum was used in the place of primary antibody as a negative control. Photomicroscopy was performed on a Zeiss Axioskop microscope with Plan-FLUAR objectives.

In situ bybridization. A 141-bp HindIII-PstI fragment of the mouse LPL cDNA (a gift of R. Zechner, University of Graz, Graz, Austria) (29) from exons 8 and 9 was isolated and subcloned into pBlueScript SK (Promega Corp., Madison, Wisconsin, USA). Antisense and sense riboprobes for LPL were prepared using ${ }^{35} \mathrm{~S}$-uridine (RNA Transcription Kit; Stratagene, La Jolla, California, USA). The sections were fixed for 30 minutes in $4 \%$ paraformaldehyde-PBS, treated for 15 minutes with proteinase $\mathrm{K}(5 \mu \mathrm{g} / \mathrm{mL})$, prehybridized for 1 hour at $55^{\circ} \mathrm{C}$ in a mixture $(0.3 \mathrm{M} \mathrm{NaCl}, 20 \mathrm{mM}$ Tris [pH 8.0], $5 \mathrm{mM}$ EDTA, $1 \times$ Denhardt's solution, 10 mM DTT, 10\% dextran sul-

\section{Table 1}

Total serum cholesterol and triglyceride levels in female C57BL/ 6 mice after transplantation with $L P L^{+/+}$, $L P L^{+/-}$, or $L P L^{-1-} \mathrm{FLCS}$

\begin{tabular}{llccccc}
\hline Group & Serum lipid & $\begin{array}{c}8 \text { weeks } \\
\text { after } \\
\text { transplant }\end{array}$ & Butterfat Diet & Butterfat Diet & Butterfat Diet & Butterfat Diet \\
$\mathrm{LPL}^{+/+} \rightarrow \mathrm{C} 57 \mathrm{BL} / 6$ & Cholesterol & $94 \pm 2$ & $124 \pm 3$ & $146 \pm 4$ & $136 \pm 4$ & $177 \pm 33$ \\
$n=15$ & Triglyceride & $82 \pm 5$ & $69 \pm 4$ & $36 \pm 5$ & $51 \pm 3$ & $51 \pm 3$ \\
$\mathrm{LPL}^{+/-} \rightarrow \mathrm{C} 57 \mathrm{BL} / 6$ & Cholesterol & $86 \pm 1$ & $123 \pm 3$ & $143 \pm 1$ & $122 \pm 6$ & $171 \pm 9$ \\
$n=12$ & Triglyceride & $71 \pm 5$ & $82 \pm 4^{\mathrm{A}}$ & $39 \pm 5$ & $41 \pm 3$ & $49 \pm 5$ \\
$\mathrm{LPL}^{-/-} \rightarrow \mathrm{C} 57 \mathrm{BL} / 6$ & Cholesterol & $84 \pm 2$ & $121 \pm 3$ & $144 \pm 2$ & $129 \pm 6$ & $175 \pm 7$ \\
$n=14$ & Triglyceride & $74 \pm 6$ & $78 \pm 8^{\mathrm{A}}$ & $37 \pm 6$ & $40 \pm 3$ & $49 \pm 4$ \\
\hline
\end{tabular}

Mice were fed a $4.5 \%$ chow diet for the first 8 weeks after transplantation, and an atherogenic diet containing $19.5 \%$ fat, $1.25 \%$ cholesterol, and $0.5 \%$ cholic acid for the remainder of the experiment. Values $(\mathrm{mg} / \mathrm{dL})$ are mean \pm SD. The number of animals in each group is indicated by $n$. ${ }^{A}$ The difference is statistically significant in comparison with the control $L P L^{+/+} \rightarrow C 57 B L / 6$ mice at that time point $(P<0.001)$.

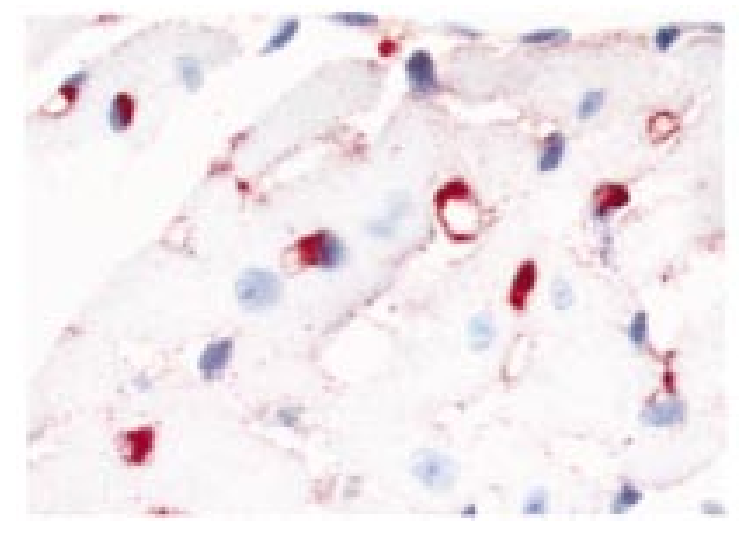

fate, $50 \%$ formamide), and, after addition of the riboprobes, incubated overnight at $55^{\circ} \mathrm{C}$. The sections were treated for 30 minutes with RNase A $(20 \mu \mathrm{g} / \mathrm{mL})$, washed, coated with autoradiographic emulsion (Kodak NTB-2), and exposed for 2-3 weeks. After development, the slides were counterstained with hematoxylin. The sense probe was used in parallel as a negative control.

\section{Results}

Mice chimeric for macrophage expression of LPL were generated by reconstituting lethally irradiated female C57BL/6 mice with FLC from female $L \mathrm{PL}^{-/-}$fetuses. The liver is the main site of hematopoiesis from days 10-16 in the developing mouse embryo, and FLCs are capable of complete reconstitution of the hematopoietic system of lethally irradiated recipient mice (30). A rapid PCR technique for LPL genotyping of tail DNA was developed, enabling identification of fetuses within 3-4 hours. An example of the PCR genotyping of fetuses from the same $\mathrm{LPL}^{-/+}$mother is shown in Figure 1a. To avoid any possible transplant incompatibility as a result of gender mismatch, the sex of the fetuses was also determined (Figure 1b). The ability to cryopreserve FLCs before transplantation enabled us to identify a number of $L P L^{-/-}$donors before the transplantation experiment.

Thirty-four female C57BL/6 mice were lethally irradiated (9 Gy) and transplanted with $5 \times 10^{6} \mathrm{LPL}^{+/+}$, $L P L^{+/-}$or $L P L^{-/-}$FLC from day 14 female fetuses. At the end of the study, genomic DNA was isolated from bone marrow of each mouse, and a change in genotype of the bone marrow was demonstrated in all $\mathrm{LPL}^{+/-} \rightarrow \mathrm{LPL}^{+/+}$ and $\mathrm{LPL}^{-/-} \rightarrow \mathrm{LPL}^{+/+}$mice (data not shown). Eight weeks after FLC transplantation, mean total serum cholesterol and triglycerides levels did not differ between the 3 groups while on a chow diet containing $4.5 \%$ fat (Table 1). The mice were then challenged with an atherogenic diet, and total serum cholesterol levels increased to the same extent in each group. A small but significant increase in serum 
triglyceride levels of the mice transplanted with $L P L^{+/-}$ and $L P L^{-1-}$ FLC was noted after 4 weeks on the atherogenic diet compared with the control mice, but this difference was not detected at any other time point during the study, making it unlikely that this was an effect of macrophage LPL genotype. The body weight of each mouse in the experiment was measured at the same time points that serum lipid levels were determined, and the mean weights did not differ between the 3 groups during the course of the experiment (data not shown). Examination of the distribution of cholesterol among the serum lipoprotein fractions by size-exclusion chromatography after 8 weeks on the atherogenic diet revealed similar lipoprotein profiles in all 3 groups with accumulation of cholesterol in VLDL and IDL ranges (Figure 2). After 8 weeks on the diet, mean HDL cholesterol levels $(\mathrm{mg} / \mathrm{dL} \pm \mathrm{SEM})$ were $38.6 \pm 3.2$, 38.8 \pm 5.0 , and $38.4 \pm 2.9$ in the $\mathrm{C} 57 \mathrm{BL} / 6$ mice transplanted with $\mathrm{LPL}^{+/+}(n=12), \mathrm{LPL}^{+/-}(n=7)$, and $\mathrm{LPL}^{-/-}(n=10)$ FLCs, respectively.

The majority of LPL on the endothelial surface is derived from muscle and adipose tissue. Therefore, one might predict that the elimination of macrophage LPL would not significantly contribute to the post-heparin LPL activity. To examine this hypothesis, plasma postheparin LPL activity was measured in 3 mice from each group after a 4-hour fast. No significant differences were detected in plasma post-heparin LPL activity 8 weeks after transplantation while still on a chow diet (data not shown), or at the end of the experiment after 19 weeks on the high-fat diet (Figure 3a). No differences were detected in adipose tissue levels of LPL activity between the 3 groups (data not shown). In contrast, LPL activity in heart tissue of the transplanted mice varied depending on the LPL genotype (Figure 3b). Heart tissue LPL activity was reduced in mice reconstituted with $\mathrm{LPL}^{+/-}$ FLC $(3.77 \pm 0.22 \mathrm{nmol} \mathrm{FFA} / \mathrm{mL} / \mathrm{h} ; P<0.05)$ and with $L P L^{-/}$FLC $(3.19 \pm 0.16 \mathrm{nmol} \mathrm{FFA} / \mathrm{mL} / \mathrm{h} ; P<0.05)$, compared with mice transplanted with $L P L^{+/+}$FLC $(4.39 \pm$ $0.18 \mathrm{nmol} \mathrm{FFA} / \mathrm{mL} / \mathrm{h}$ ). This finding was further investigated by examining the distribution of macrophages in the myocardium. Immunocytochemistry with the macrophage-specific mAb MOMA-2 revealed that the myocardium is studded with macrophages (Figure 4), explaining the small but significant stepwise decrease in LPL activity of heart tissue that was detected in mice reconstituted with $\mathrm{LPL}^{+/-}$and $\mathrm{LPL}^{-/-}$macrophages.

After 19 weeks on the atherogenic diet, the aortic lesions in all 3 groups consisted mainly of foam cells of macrophage origin that reacted with the antimacrophage antibody MOMA-2 (Figure 5a). Fibrous caps were essentially absent in the lesions. Aortic macrophages in the mice transplanted with $\mathrm{LPL}^{+/+}$FLC immunostained with anti-LPL antibodies (Figure 5b). In contrast, macrophages in the aortic lesions of mice reconstituted with $L P L^{-/-}$FLCs were negative for staining with anti-LPL antibodies, which reacted only with surrounding extracellular matrix and smooth muscle cells of the vessel (Fig-
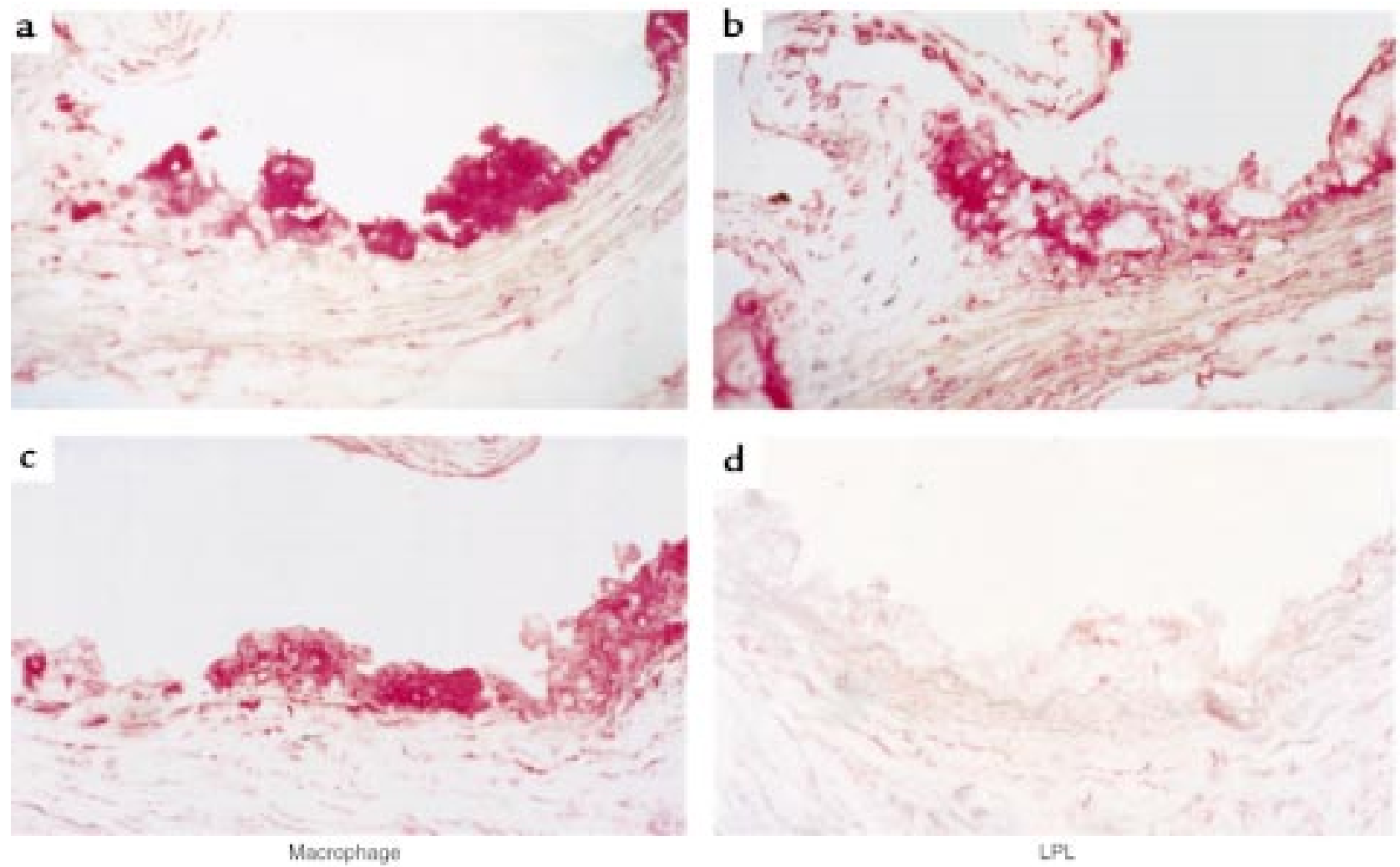

\section{Figure 5}

Immunocytochemical detection of macrophages and $L P L$ in proximal aorta of $L P L^{+/+} \rightarrow C 57 B L / 6(\mathbf{a}$ and $\mathbf{b})$ and $L P L^{-/-} \rightarrow C 57 B L / 6(\mathbf{c}$ and $\mathbf{d})$ mice Macrophages are stained with rat mAb MOMA-2, and LPL is detected with a chicken antibody to recombinant human LPL. Note that LPL expression in control mice is colocalized with macrophages, whereas macrophages in $L P L^{-/-} \rightarrow C 57 B L / 6$ mice do not stain for LPL. $\times 40$. 

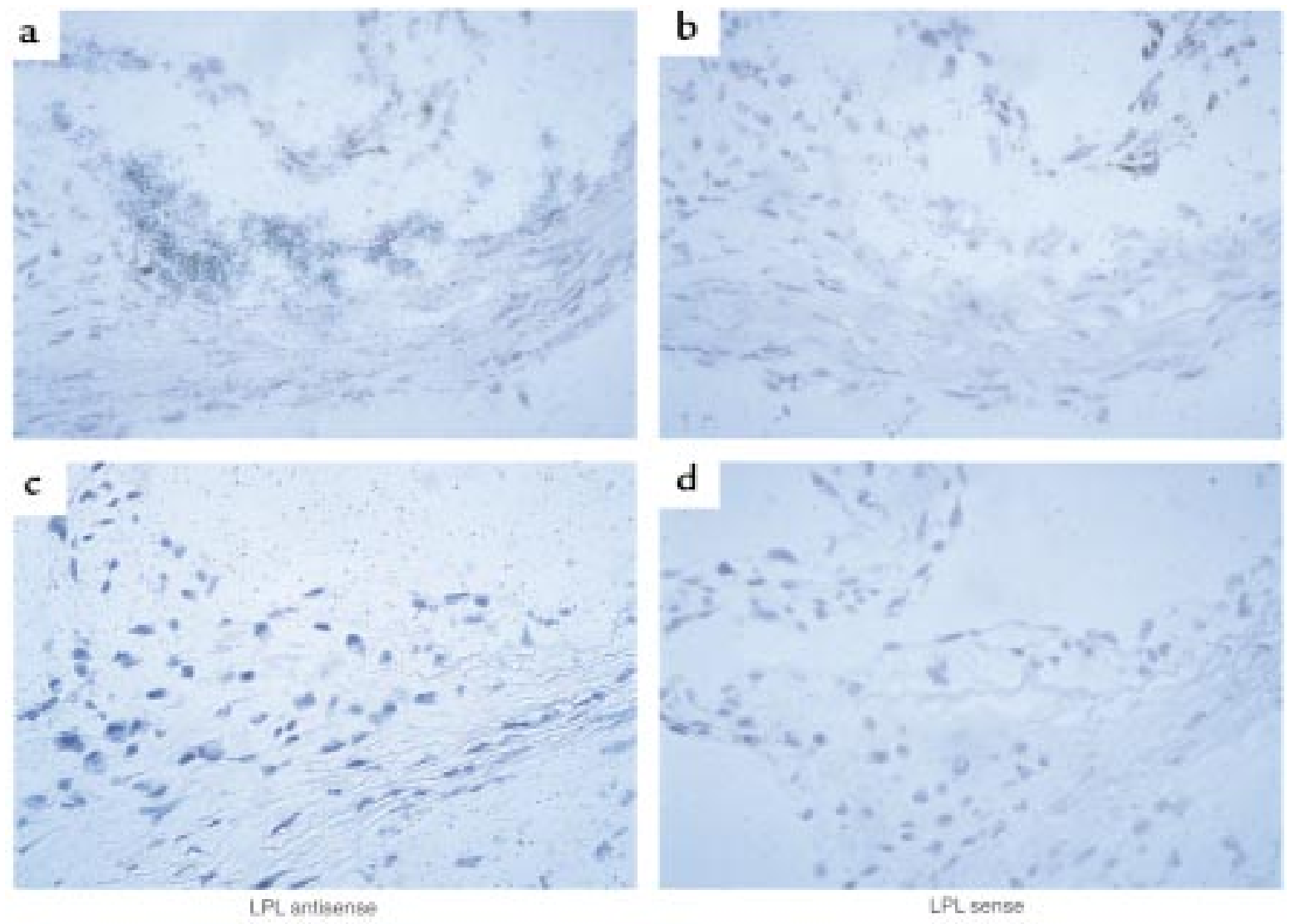

\section{Figure 6}

LPL mRNA expression in aortic lesions of mice transplanted with $L P L^{+/+}$or $L P L^{-/-}$FLCs. Expression of LPL mRNA is detected by hybridization of the antisense probe to mouse $L P L$ in foam cell lesions of $L P L^{+/+} \rightarrow C 57 B L / 6$ mice (a) but not of $L P L^{-/-} \rightarrow C 57 B L / 6$ mice $(\mathbf{c})$. Shown in $\mathbf{b}$ and $\mathbf{d}$ are the corresponding control serial sections after hybridization with the sense probe for $L P L$. $\times 40$.

ure 5d). LPL mRNA expression was detected by in situ hybridization in foam cell lesions of the proximal aortae of the $\mathrm{LPL}^{+/+} \rightarrow \mathrm{C} 57 \mathrm{BL} / 6$ mice (Figure $6 \mathrm{a}$ ), but no specific hybridization was seen with the sense control (Figure 6b). LPL mRNA expression was detected in myocardial cells, but not foam cells, of $\mathrm{LPL}^{-/} \rightarrow \mathrm{C} 57 \mathrm{BL} / 6$ mice (Figure $6 \mathrm{c}$ ), and no specific hybridization was seen with the sense control (Figure 6d).

Quantitative analysis of the extent of atherosclerosis was performed by measuring the extent of oil red $\mathrm{O}$ staining of cryosections from the proximal aorta as described previously $(18,19)$. The mean lesion area $\left(\mu \mathrm{m}^{2}\right.$ \pm SEM) in the proximal aorta was reduced by $55 \%$ ( $P<$ $0.002)$ in $\mathrm{LPL}^{-/-} \rightarrow \mathrm{C} 57 \mathrm{BL} / 6$ mice $(9,677 \pm 1,478) \mathrm{com}$ pared with $\mathrm{LPL}^{+/+} \rightarrow \mathrm{C} 57 \mathrm{BL} / 6(21,637 \pm 3,284)$ and by $45 \%$ $(P<0.031)$ compared with $L P L^{+/-} \rightarrow C 57 B L / 6(17,453 \pm$ $3,126)$ mice (Figure 7). The mean lesion area in the $\mathrm{LPL}^{+/-} \rightarrow \mathrm{C} 57 \mathrm{BL} / 6$ mice was $19 \%$ less than in the $\mathrm{LPL}^{+/+} \rightarrow \mathrm{C} 57 \mathrm{BL} / 6$ mice, but this difference was not statistically significant $(P=0.368)$. The mean macrophage area $\left(\mu \mathrm{m}^{2} \pm \mathrm{SEM}\right)$ in mice receiving $\mathrm{LPL}^{+/+}(n=7), \mathrm{LPL}^{+/-}$ $(n=8)$, and $L P L^{-/-}(n=8)$ FLCs was $11,260 \pm 1,690,8,146$ $\pm 1,698$, and 3,560 \pm 599 , respectively $\left(P=0.002\right.$ for $L P L^{-/}$ vs. $L P L^{+/+} ; P=0.023$ for $L P L^{-/-}$vs. $L P L^{+/-}$). Thus, there was a significant decrease in the macrophage area and the lipid staining area in mice transplanted with $L P L^{-/-}$FLCs compared with mice transplanted with $\mathrm{LPL}^{+/+}$and $\mathrm{LPL}^{+/}$
FLCs. In fact, the ratio of macrophage area/lipid staining was less in the mice transplanted with $L P L^{-/-}$FLC than with $L P L^{+/-}$or $L P L^{+/+}$FLCs: 0.37 vs. 0.47 and 0.52 , respectively. Figure 8 shows an examination of the distribution of the mean lesion area per section in the 300 $\mu \mathrm{m}$ of the proximal aorta analyzed in this experiment. In the more proximal region of the aorta, there is a significant difference in the mean lesion area per section in the $\mathrm{LPL}^{+/-} \rightarrow \mathrm{C} 57 \mathrm{BL} / 6$ compared with $\mathrm{LPL}^{+/+} \rightarrow \mathrm{C} 57 \mathrm{BL} / 6$ mice. This difference between these 2 groups is lost in the more distal sections (Figure 8). On linear regression analysis, there was no correlation between the lesion size and serum levels of total cholesterol $(n=34, r=0.262, P$ $=0.134)$ or HDL cholesterol $(r=0.09, P=0.671)$ in mice transplanted with $L P L^{+/+}, L P L^{+/-}$and $L P L^{-/-}$FLCs.

\section{Discussion}

The present study was undertaken to analyze in vivo the role of macrophage LPL expression in atherosclerotic lesion formation. For this purpose, mice chimeric for macrophage LPL gene expression were created by transplanting lethally irradiated female C57BL/6 mice with FLCs from day $14 \mathrm{LPL}^{-/-}, \mathrm{LPL}^{+/-}$, or $L P L^{+/+}$fetuses. Reconstitution of $\mathrm{C} 57 \mathrm{BL} / 6$ mice with $\mathrm{LPL}^{-/-}$and $\mathrm{LPL}^{+/-}$ macrophages did not result in significant changes in serum total cholesterol or triglyceride levels when the mice were fed a chow diet or a high-fat atherogenic diet. After 19 
weeks on an atherogenic diet, the mean aortic lesion area in $\mathrm{LPL}^{-1-} \rightarrow \mathrm{C} 57 \mathrm{BL} / 6$ mice was $45 \%$ less than in $L P L^{+/-} \rightarrow C 57 B L / 6$ mice and $55 \%$ less than in $\mathrm{LPL}^{+/+} \rightarrow \mathrm{C} 57 \mathrm{BL} / 6$ mice. Therefore, LPL null macrophages are less prone to progress to foam cells than $\mathrm{LPL}^{+/+}$or $L P L^{+/-}$ macrophages under similar atherogenic conditions. On the basis of these observations, we conclude that in the setting of an atherogenic diet, macrophage expression of LPL promotes foam cell formation and atherosclerosis in vivo.

The macrophage expresses a variety of genes that may contribute to lipoprotein metabolism and the pathogenesis of atherosclerosis. Murine bone marrow transplantation experiments using gene-targeted mice, as either donors or recipients, provide a useful approach to examining the role of macrophage gene expression in lipoprotein metabolism and atherosclerosis (18). The rapid postnatal lethality of homozygous LPL deficiency makes it difficult to identify viable $L P L^{-/-}$offspring as donors for bone marrow transplantation experiments. In the current study, FLC transplantation was used as an alternative approach for developing C57BL/6 mice chimeric for macrophage LPL gene expression. FLCs offer several potential advantages compared with adult bone marrow as a source of donor hematopoietic stem cells in transplantation experiments. In competitive repopulation studies, FLCs have been shown to be more efficient in repopulating irradiated recipient mice than were adult bone marrow cells (30). Because FLCs are immunologically naive and lack mature $\mathrm{T}$ cells, the risk of graft versus host disease is effectively eliminated, even during transplantation across major or minor histocompatibility barriers (22). Thus, FLC transplantation should prove to be a useful approach in examining the role of other genes expressed by the macrophage in atherosclerosis, when homozygous disruption of the gene results in embryonic or perinatal lethality that does not affect viability of the hematopoietic cells.

LPL is the rate-limiting enzyme for the hydrolysis of plasma lipoprotein triglyceride. LPL is synthesized in parenchymal cells, but it functions to hydrolyze plasma triglycerides at the luminal surface of the vascular endothelium (31). Muscle and adipose tissues are the predominant sources of LPL production (1). Macrophages also synthesize LPL, but the relative contribution of macrophage LPL to the hydrolysis of plasma triglycerides in vivo has not been examined previously. The adult mouse contains about $1 \times 10^{8}$ macrophages (32); therefore, macrophages might contribute significantly to the functional LPL on the endothelial surface. $\mathrm{LPL}^{+/-}$mice generated by homologous recombination are hypertriglyceridemic compared with wild-type littermates, demonstrating that there is a limit to the enzymatic efficiency of LPL (20). In the current study, serum lipid levels, lipoprotein distributions, and plasma post-heparin LPL activity did not differ in mice reconstituted with $\mathrm{LPL}^{-/-}$, $\mathrm{LPL}^{+/-}$, or $\mathrm{LPL}^{+/+}$FLCs. These results demonstrate that macrophage LPL expression does not significantly contribute to the metabolism of plasma lipoproteins or the pool of LPL attached to the vascular endothelium. However, a contribution of macrophage LPL to lipoprotein metabolism might be detectable under conditions in which LPL activity is limiting, such as in $\mathrm{LPL}^{+/-}$or $\mathrm{LPL}^{-/-}$

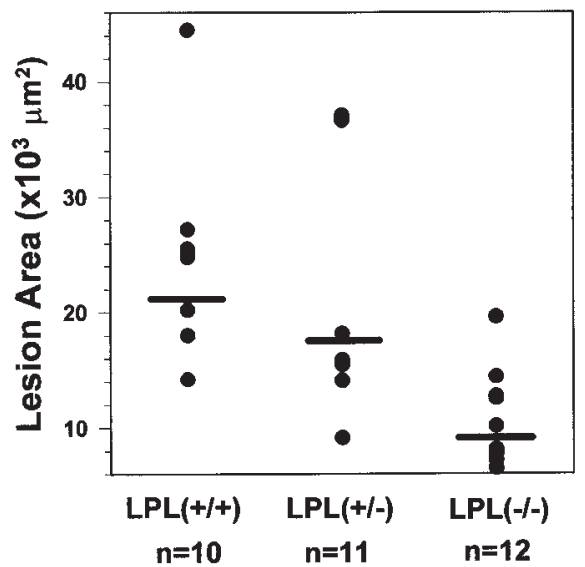

Figure 7

Quantification of atherosclerotic lesion area in mice transplanted with $L P L^{+/+}, L P L^{+/-}$, and $L P L^{-/-}$FLCs. The extent of atherosclerotic lesions was quantified after 19 weeks of the atherogenic diet, using oil red O-stained sections from $300 \mu \mathrm{m}$ of the proximal aorta. Fifteen alternate $10-\mu \mathrm{m}$ sections from the proximal aorta were examined for each mouse, using a computer-assisted video imaging system. Data are represented as the average mean lesion area for each group. $P<0.001 \mathrm{vs.} L P L^{+/+} \rightarrow C 57 B L / 6$ mice; $P<0.002$ vs. $L P L^{+/-} \rightarrow C 57 B L / 6$.

recipient mice. In contrast, a significant stepwise $14 \%$ and $27 \%$ decrement in the LPL activity of heart tissue was detected in C57BL/ 6 mice reconstituted with $L P L^{+/-}$and $L P L^{-/-}$FLC, respectively, compared with $L P L^{+/+}$FLC. Thus, we were able to detect a gene-dosage effect of macrophage LPL activity in a tissue known to have a high level of LPL expression from myocardial cells.

The role of LPL in atherogenesis is complex and defies classification as simply proatherogenic or antiatherogenic. LPL has been proposed to influence atherogenesis both through its effects on the plasma lipoproteins and by direct effects in the artery wall. Familial LPL deficiency has

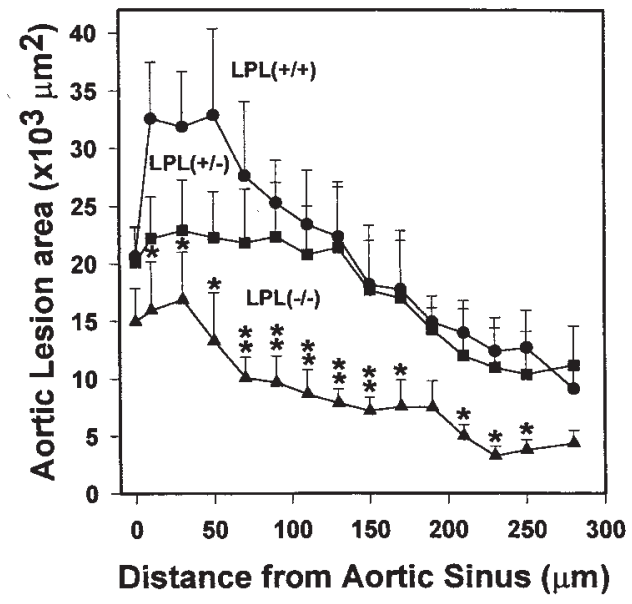

\section{Figure 8}

Comparison of the mean lesion area in progressive sections of the proximal aorta from mice transplanted with $\mathrm{LPL}^{+/+}, \mathrm{LPL}^{+/-}$, and $\mathrm{LPL}^{-/-}$FLCs. Mean lesion area per section for 15 alternate $10-\mu \mathrm{m}$ sections spanning the proximal aorta starting from the aortic sinus, with a $10-\mu \mathrm{m}$ interval between sections; error bars represent the SEM. ${ }^{*} P<0.05 \mathrm{vs}$. $L P L^{+/+} \rightarrow C 57 B L / 6$ mice. ${ }^{*} P<0.05$ vs. $L P L^{+/+} \rightarrow C 57 B L / 6$ and $L P L^{+/-} \rightarrow C 57 B L / 6$ mice. 
been viewed as nonatherogenic because chylomicrons are too large to penetrate the endothelium and because plasma levels of LDL cholesterol are low (1). However, the development of premature atherosclerosis in 4 patients with familial chylomicronemia syndrome due to mutations in the LPL gene has been recently reported (33), indicating that reduced LPL catalytic activity can be associated with premature atherosclerosis. A common LPL mutation (Asn291Ser) has been reported to be associated with low levels of HDL cholesterol and premature coronary artery disease $(34,35)$, indicating that a single common mutation in the LPL gene may increase susceptibility to atherosclerosis in certain populations. In response to an atherogenic diet, $\mathrm{LPL}^{-/+}$mice become more dyslipidemic but develop the same extent of atherosclerosis as do $\mathrm{LPL}^{+/+}$mice (36), suggesting that reduced expression of LPL in the artery wall of the $L P L^{+/-}$mice may have counterbalanced the atherogenic effect of the dyslipidemia. In contrast, overexpression of LPL in transgenic mice results in decreased serum triglycerides, increased HDL cholesterol, and protection from atherosclerosis (37-40). A complex picture arises from these observations in which the effects of LPL on the plasma lipoproteins and in the artery wall may have divergent roles in atherogenesis.

Zilversmit proposed that LPL activity in the artery wall contributes to the pathogenesis of atherosclerosis, and he later observed that cholesterol-rich atherosclerotic areas of the rabbit aorta had increased LPL activity (5). In the current studies, we demonstrated, by immunocytochemistry and in situ hybridization, that macrophage-derived foam cells in the aortic lesions of $\mathrm{LPL}^{-/-} \rightarrow \mathrm{C} 57 \mathrm{BL} / 6$ mice did not express LPL. This result is consistent with our previous observation that bone marrow transplantation results in the reconstitution of the arterial wall with macrophages and macrophage-derived foam cells of donor origin (19). The absence of immunodetectable LPL associated with macrophage-derived foam cells in the aortic lesions of $\mathrm{LPL}^{-/-} \rightarrow \mathrm{C} 57 \mathrm{BL} / 6$ mice indicates that most of the LPL associated with macrophage-derived foam cells is derived from synthesis by the macrophages locally, rather than from the plasma compartment or muscle cells. The current studies demonstrate in vivo that LPL expression in the artery wall can influence the development of atherosclerosis independently of its effects on the plasma lipoproteins.

Macrophage LPL has been proposed to promote atherosclerosis through a variety of mechanisms including: (a) enhancing monocyte recruitment and retention in the artery wall (13) (b) promoting lipoprotein internalization and lipid accumulation by macrophages through local lipolysis of lipoproteins $(14,15)$, and (c) increasing retention of lipoproteins in the extracellular matrix through LPL-mediated bridging with proteoglycans (10). That the lesions in the $L P L^{-/-} \rightarrow C 57 B L / 6$ consisted of macrophage-derived foam cells suggests that macrophage LPL is not absolutely critical for macrophage retention in the artery wall. If local catalytic activity of macrophage LPL serves to promote lipid accumulation by the macrophage, the amount of LPL produced by $\mathrm{LPL}^{+/-}$macrophages might suffice to serve this function; whereas, a gene-dosage effect of macrophage LPL expression might be more likely to be seen if bridging were the dominant mechanism. Therefore, the observation that the mean lesion area in the $\mathrm{LPL}^{+/-} \rightarrow \mathrm{C} 57 \mathrm{BL} / 6$ mice was not significantly different than in the $\mathrm{LPL}^{+/+} \rightarrow \mathrm{C} 57 \mathrm{BL} / 6$ mice is of interest, as it suggests that the catalytic activity of macrophage LPL may be important in lipid accumulation by the macrophage. In the more proximal region of the aorta, where lesions develop first, the lesion area in the $\mathrm{LPL}^{+/-} \rightarrow \mathrm{C} 57 \mathrm{BL} / 6$ mice was clearly intermediate in comparison with the mice reconstituted with $L P L^{-/-}$and $L P L^{+/+}$FLCs, suggesting a gene-dosage effect. Regardless of the mechanism, the current results provide strong evidence for an important role for macrophage LPL in promoting foam cell formation in vivo. Furthermore, it should be noted that the catalytic and bridging functions of LPL are not mutually exclusive and may both contribute significantly to macrophage lipid accumulation in vivo. Further studies will be required to elucidate which of these mechanisms pertain in vivo.

In summary, mice chimeric for macrophage LPL gene expression were created by transplanting lethally irradiated female C57BL/ 6 mice with FLCs from day $14 \mathrm{LPL}^{-/-}$, $\mathrm{LPL}^{+/-}$, or $\mathrm{LPL}^{+/+}$fetuses. When challenged with an atherogenic diet, $\mathrm{C} 57 \mathrm{BL} / 6$ mice reconstituted with $\mathrm{LPL}^{-/-}$macrophages developed significantly less atherosclerosis than did C57BL/6 mice reconstituted with $\mathrm{LPL}^{+/-}$or $\mathrm{LPL}^{+/+}$macrophages, in the absence of significant differences in serum lipids or lipoprotein profiles. Therefore, we conclude that under atherogenic conditions, macrophage LPL expression promotes foam cell formation and atherosclerosis in vivo.

\section{Acknowledgments}

We are grateful to Lawrence Chan for antibodies to LPL, and to Rudolf Zechner for LPL cDNA. This work was supported by an American Heart Association (AHA) Established Investigator Award $(9740040 \mathrm{~N})$ to M.F. Linton, and in part by National Institutes of Health grants HL-53989 and HL-58427. S. Fazio is an AHA Established Investigator (96001900). V.R. Babaev is supported by a Fellowship Award from the Southeast Affiliate of the AHA (9840052SE).

1. Brunzell, J.D. 1995. Familial lipoprotein lipase deficiency and other causes of the chylomicronemia syndrome. In The metabolic basis of inherited disease. Volume 2. C.R. Scriver, A.L. Beaudet, W.S. Sly, and D. Valle, editors. McGraw-Hill. New York, NY. 1913-1932.

2. Saxena, U., Klein, M.G., and Goldberg, I.J. 1991. Identification and characterization of the endothelial cell surface lipoprotein lipase receptor. $J$. Biol. Chem. 266:17516-17521.

3. Yla-Herttuala, S., et al. 1991. Macrophages and smooth muscle cells express lipoprotein lipase in human and rabbit atherosclerotic lesions. Proc. Natl. Acad. Sci. USA. 88:10143-10147.

4. O'Brien, K.D., Gordon, D., Deeb, S., Ferguson, M., and Chait, A. 1992. Lipoprotein lipase is synthesized by macrophage-derived foam cells in human coronary atherosclerotic plaques. J. Clin. Invest. 89:1544-1550.

5. Zilversmit, D.B. 1979. Atherogenesis: a postprandial phenomenon. Circulation. 60:473-485.

6. Olivecrona, G., and Olivecrona, T. 1995. Triglyceride lipases and atherosclerosis. Curr. Opin. Lipidol. 6:291-305.

7. Beisiegel, U., Weber, W., and Bengtsson-Olivecrona, G. 1991. Lipoprotein lipase enhances the binding of chylomicrons to low density lipoprotein receptor-related protein. Proc. Natl. Acad. Sci. USA. 88:8342-8346.

8. Rumsey, S.C., Obunike, J.C., Arad, Y., Deckelbaum, R.J., and Goldberg, I.J. 1992. Lipoprotein lipase-mediated uptake and degradation of low density lipoproteins by fibroblasts and macrophages. J. Clin. Invest. 90:1504-1512.

9. Tabas, I., et al. 1993. Lipoprotein lipase and sphingomyelinase synergistically enhance the association of atherogenic lipoproteins with smooth muscle cells and extracellular matrix. J. Biol. Chem. 268:20419-20432. 
10. Saxena, U., Klein, M.G., Vanni, T.M., and Goldberg, I.J. 1992. Lipoprotein lipase increases low density lipoprotein retention by subendothelial cell matrix. J. Clin. Invest. 89:373-380.

11. Goldberg, I.J. 1996. Lipoprotein lipase and lipolysis: central roles in lipoprotein metabolism and atherogenesis. J. Lipid Res. 37:693-707.

12. Merkel, M., et al. 1998. Catalytically inactive lipoprotein lipase expression in muscle of transgenic mice increases very low density lipoprotein uptake: direct evidence that lipoprotein lipase bridging occurs in vivo. Proc. Natl. Acad. Sci. USA. 95:13841-13846.

13. Saxena, U., Kulkarni, N.M., Ferguson, E., and Newton, R.S. 1992 Lipoprotein lipase-mediated lipolysis of very low density lipoproteins increases monocyte adhesion to aortic endothelial cells. Biochem. Biophys. Res. Commun. 189:1653-1658.

14. Lindqvist, P.L., Ostlund-Lindqvist, A.M., Witztum, J.L., Steinberg, D., and Little, J.A. 1983. The role of lipoprotein lipase in the metabolism of triglyceride-rich lipoproteins by macrophages. J. Biol. Chem. 258:9086-9092.

15. Aviram, M., Bierman, E.L., and Chait, A. 1987. Modification of low density lipoprotein by lipoprotein lipase or hepatic lipase induces enhanced uptake and cholesterol accumulation in cells. J. Biol. Chem. 263:15416-15422.

16. Lucas, M., Iverius, P.H., Strickland, D.K., and Mazzone, T. 1997. Lipoprotein lipase reduces secretion of apolipoprotein E from macrophages. J. Biol. Chem. 272:13000-13005.

17. Renier, G., Skamene, E., DeSanctis, J.B., and Radzioch, D. 1993. High macrophage lipoprotein lipase expression and secretion are associated in inbred murine strains with susceptibility to atherosclerosis. Arterioscler. Thromb. 13:190-196.

18. Linton, M.F., Atkinson, J.B., and Fazio, S. 1995. Prevention of atherosclerosis in apoE deficient mice by bone marrow transplantation. Science. 267:1034-1037.

19. Fazio, S., et al. 1997. Increased atherosclerosis in C57BL/6 mice reconstituted with apolipoprotein E null macrophages. Proc. Natl. Acad. Sci. USA. 94:4647-4652.

20. Coleman, T., et al. 1995. COOH-terminal disruption of lipoprotein lipase in mice is lethal in homozygotes, but heterozygotes have elevated triglycerides and impaired enzyme activity. J. Biol. Chem. 270:12518-12525.

21. Weinstock, P.H., et al. 1995. Severe hypertriglyceridemia, reduced high density lipoprotein, and neonatal death in lipoprotein lipase knockout mice. J. Clin. Invest. 96:2555-2568.

22. Tocci, A., Rezzoug, F., Aitouche, A., and Touraine, J.-L. 1994. Comparison of fresh, cryopreserved and cultured haematopoietic stem cells from fetal liver. Bone Marrow Transplant. 13:641-648.

23. Busler, D.E., and Li, S.W. 1996. Rapid screening of transgenic type II and type XI collagen knock-out mice with three-primer PCR. Biotechniques. 21:1002-1004.

24. Dreesen, J.C., Dumoulin, J.C., Evers, J.L., Geraedts, J.P., and Pieters, M.H. 1995. Multiplex polymerase chain reaction for sex determination of single mouse blastomeres. Hum. Reprod. 10:743-748.
25. Seip, R.L., Angelopoulos, T.J., and Semenkovich, C.F. 1995. Exercise induces human lipoprotein lipase gene expression in skeletal muscle but not adipose tissue. Am. J. Physiol. 268:E229-E236.

26. Paigen, B., Morrow, A., Holmes, P.A., Mitchell, D., and Williams, R.A. 1987. Quantitative assessment of atherosclerotic lesions in mice. Atherosclerosis. 68:231-240.

27. Purcell-Huynh, D.A., et al. 1995. Transgenic mice expressing high levels of human apolipoprotein B develop severe atherosclerotic lesions in response to a high-fat diet. J. Clin. Invest. 95:2246-2257.

28. Potenz, R., Lo, J.Y., Zsigmond, E., Smith, L.C., and Chan, L. 1996. Human lipoprotein lipase: production in vitro, purification, and generation of polyclonal antibody. Methods Enzymol. 263:319-326.

29. Zechner, R., Newman, T.C., Steiner, E., and Breslow, J.L. 1991. The structure of the mouse lipoprotein lipase gene: a B1 repetitive element is inserted into the $3^{\prime}$ untranslated region of the mRNA. Genomics. 11:62-76.

30. Jordan, C.T., et al. 1995. Long-term repopulating abilities of enriched fetal liver stem cells measured by competitive repopulation. Exp. Hematol. 23:1011-1015.

31. Eckel, R.H. 1989. Lipoprotein lipase a multifunctional enzyme relevant to common metabolic diseases. N. Engl. J. Med. 320:1060-1068.

32. Lee, S.H., Starkey, P.M., and Gordon, S. 1985. Quantitative analysis of total macrophage content in adult mouse tissues. Immunochemical studies with monoclonal antibody F4/80. J. Exp. Med. 161:475-489.

33. Benlian, P., et al. 1996. Premature atherosclerosis in patients with familial chylomicronemia caused by mutations in the lipoprotein lipase gene. N. Engl. J. Med. 335:848-854.

34. Wittrup, H.H., et al. 1997. A common substitution (Asn291Ser) in lipoprotein lipase is associated with increased risk of ischemic heart disease. J. Clin. Invest. 99:1606-1613.

35. Reymer, P.W.A., et al. 1995. A lipoprotein lipase mutation (Asn291Ser) is associated with reduced HDL cholesterol levels in premature atherosclerosis. Nat. Genet. 10:28-34.

36. Semenkovich, C.F., Coleman, T., and Daugherty, A. 1998. Effects of heterozygous lipoprotein lipase deficiency on diet-induced atherosclerosis in mice. J. Lipid Res. 39:1141-1151.

37. Shimada, M., et al. 1993. Overexpression of human lipoprotein lipase in transgenic mice. J. Biol. Chem. 268:17924-17929.

38. Liu, M.S., et al. 1994. Alteration of lipid profiles in plasma of transgenic mice expressing human lipoprotein lipase. J. Biol. Chem. 269:11417-11424

39. Zsigmond, E., et al. 1994. Transgenic mice expressing human lipoprotein lipase driven by the mouse metallothionein promoter. J. Biol. Chem. 269:18757-18766

40. Shimada, M., et al. 1996. Suppression of diet-induced atherosclerosis in low density lipoprotein receptor knockout mice overexpressing lipoprotein lipase. Proc. Natl. Acad. Sci. USA. 93:7242-7246. 